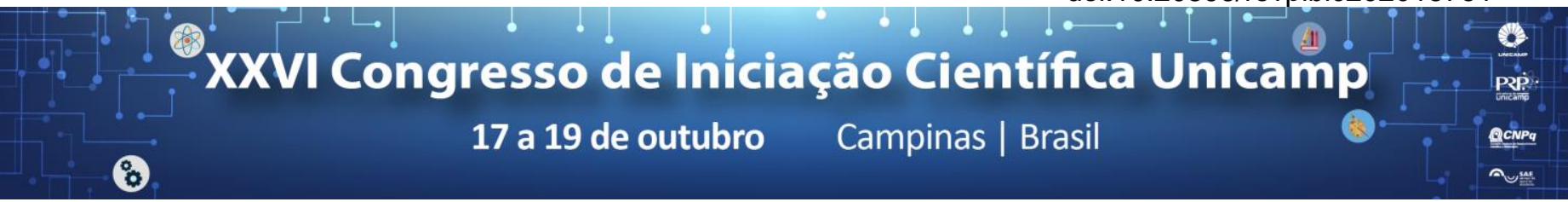

\title{
Análise das alterações morfológicas e respostas mecânicas do osso alveolar em ratos submetidos à hipofunção oclusal
}

\section{Karina Satiko Ivasse*, Ana Cláudia Rossi, Felippe Bevilacqua Prado, Alexandre Rodrigues Freire.}

\section{Resumo}

O objetivo deste estudo foi analisar as alterações do osso alveolar em ratos sob hipofunção oclusal. Após desgaste do incisivo central superior direito dois grupos de animais mantiveram-se em dieta normal durante 7 e 14 dias. Foram realizadas microtomografias para avaliação dos tecidos de suporte dos dentes desgastados, em que observou-se aumento do espaço periodontal nos dois grupos, sendo maior aos 14 dias. A simulação computacional mostrou redução na quantidade de deformações no osso alveolar de suporte do incisivo central desgastado.

\section{Palavras-chave:}

mecanobiologia, hipofunção oclusal, análise de elementos finitos.

\section{Introdução}

Uma redução da atividade mecânica pode levar a um aumento da perda óssea. A maxila e a mandíbula recebem estimulação proveniente da mordida e mastigação, o que é importante para investigar a relação entre função e morfologia destes ossos ${ }^{1}$. O objetivo deste estudo foi analisar a orientação trabecular do osso alveolar maxilar em ratos adultos submetidos à uma condição de hipofunção oclusal.

\section{Resultados e Discussão}

Foram utilizados 18 ratos machos (Rattus norvegicus albinus), linhagem Wistar, com 2 meses de idade (200250g), provenientes do CEMIB-UNICAMP. Foram mantidos em gaiolas coletivas (quatro animais/caixa), com temperatura em $22 \pm 2^{\circ} \mathrm{C}$, ciclo de luz controlado (12/12 h) e acesso livre à água e ração. Os ratos foram aleatoriamente distribuídos em grupos distintos para os experimentos. No grupo $1(n=9)$ foi realizado o desgaste do dente incisivo central superior (lado direito), simulando uma situação de hipofunção oclusal e os ratos foram eutanasiados 7 dias após à exodontia. O grupo $2(n=9)$ foi realizada o mesmo procedimento, porém os ratos foram eutanasiados 14 dias após o desgaste. Os procedimentos foram realizados sob anestesia geral utilizando solução de quetamina $(40-87 \mathrm{mg} / \mathrm{kg})$ e relaxante muscular xilasina $(5-13 \mathrm{mg} / \mathrm{kg})$, por via intraperitoneal. Uma vez verificada a sedação e os sinais de anestesia, foi realizado o desgaste do incisivo superior direito, utilizando ponta diamantada em alta rotação sob refrigeração. Após eutanásia nos períodos estabelecidos previamente, a cabeça foi desarticulada do corpo e fixada em solução de formol a $10 \%$ e tampão fosfato $0,1 \mathrm{M}(\mathrm{pH} 7,4)$, durante $24 \mathrm{~h}$ a $4^{\circ} \mathrm{C}$. As peças foram submetidas à microtomografia computadorizada em um microtomógrafo (Skyscan 1174). Após o escaneamento, estas imagens foram exportadas para o software NRecon Reconstruction (SkyScan, Leuven, Bélgica), no qual foram reconstruídas tridimensionalmente. Após a reconstrução tridimensional de cada maxila direita, a obtenção dos dados de volume do espaço periodontal foi realizada no software CT-Analyzer (figura 1) (SkyScan, Leuven, Bélgica). Os dados de volume foram submetidos a teste estatístico, o nível de significância adotado foi de $5 \%(\alpha=0,05)$ e as deformações mecânicas foram analisadas pela quantidade de deformações $(\varepsilon)$. A análise da região de interesse (espaço periodontal do incisivo superior direito) permitiu verificar que no grupo 1 , o valor médio de volume foi de $31,62 \mu \mathrm{m}^{3}$ e no grupo 2 foi de $36,01 \mu \mathrm{m}^{3}$. Já o grupo controle apresentou volume de $28,24 \mu^{3}$. No grupo experimental, foi observado diminuição da quantidade de deformações na região de interesse comparado ao grupo controle (figura 2).

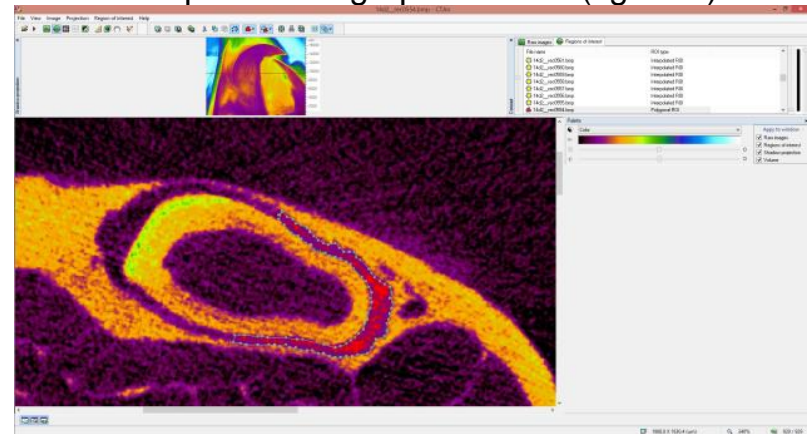

Figura 1. Análise do volume do espaço periodontal para avaliação da remodelação óssea no software CTAnalyzer (Bruker).

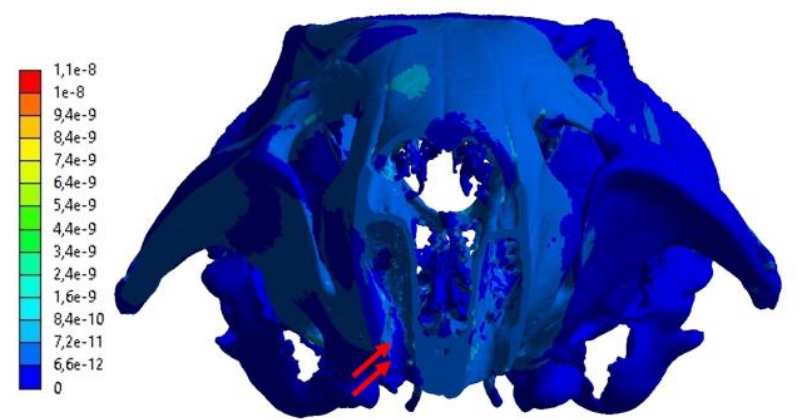

Figura 2. Análise das deformações ósseas. As setas indicam a área com menores quantidade de deformações no osso alveolar ao nível do terço médio do alvéolo. Grupo experimental.

\section{Conclusões}

Os resultados deste estudo permitiram compreender que a hipofunção oclusal alterou a morfologia periodontal demonstrada pela diminuição das deformações ósseas observadas na simulação computacional.

\section{Agradecimentos}

Os autores são gratos ao apoio financeiro recebido pelo Conselho Nacional de Desenvolvimento Científico e Tecnológico (PIBIC-EM-CNPq).

${ }^{1}$ Kunii R, Yamaguchi M, Aoki Y, Watanabe A, Kasai K. Effects of experimental occlusal hypofunction, and its recovery, on mandibular bone mineral density in rats. Eur J Orthod 2008; 30:52. 